\title{
Gamma-Klotho exhibits multiple roles in tumor growth of human bladder cancer
}

\author{
Shunta Hori ${ }^{1}$, Makito Miyake ${ }^{1}$, Yoshihiro Tatsumi ${ }^{1}$, Yosuke Morizawa ${ }^{1}$, Yasushi \\ Nakai ${ }^{1}$, Sayuri Onishi ${ }^{1}$, Kenta Onishi ${ }^{1}$, Kota Iida ${ }^{1}$, Daisuke Gotoh ${ }^{1}$, Nobumichi \\ Tanaka $^{1}$ and Kiyohide Fujimoto ${ }^{1}$ \\ ${ }^{1}$ Department of Urology, Nara Medical University, Kashihara-Shi, Nara 634-8522, Japan \\ Correspondence to: Kiyohide Fujimoto, email: kiyokun@naramed-u.ac.jp \\ Keywords: urothelial carcinoma; gamma-Klotho; apoptosis; epithelial-mesenchymal transition; cancer prognosis \\ Received: October 02, 2017 \\ Accepted: February 24, 2018 \\ Published: April 13, 2018 \\ Copyright: Hori et al. This is an open-access article distributed under the terms of the Creative Commons Attribution License 3.0 \\ (CC BY 3.0), which permits unrestricted use, distribution, and reproduction in any medium, provided the original author and source \\ are credited.
}

\section{ABSTRACT}

\begin{abstract}
Alpha-Klotho $(K L \alpha)$ and beta-Klotho $(K L \beta)$ have recently been reported to correlate with cancer prognosis in some malignancies and we previously reported the association between $K L \alpha, K L \beta$, and urothelial carcinoma of the bladder (UCB), indicating that $K L \beta$ acts as a tumor promoter. However, the association between gamma-Klotho $(K L \gamma)$ and cancer prognosis remains unclear. In the present study, we evaluated the association between $K L \gamma$ and UCB. To evaluate the effect of $K L \gamma$ on human bladder cancer cell lines in vitro assays were performed. Exogenous $\mathrm{KL} \gamma$ increased the ability of human bladder cancer cells to proliferate, migrate, invade, form colonies, and provide anchorage-independent growth potential. In in vivo assays, eighteen mice bearing xenografts inoculated using UM-UC-3, were randomly divided into three groups and treated with a small interfering RNA (siRNA) by intratumoral administration once a week for four weeks. Knockdown of KL $\gamma$ with siRNA led to a dramatic change in tumor growth and suggested that $K L \gamma$ had effects on tumor growth, including promotion of cell proliferation, inhibition of apoptosis, and enhancement of the epithelial-mesenchymal transition. To confirm the study, human tissue samples were used and patients were divided into two groups according to KL $\gamma$ expression level. High expression of $\mathrm{KL} \gamma$ was significantly associated with higher stage and grade cancer and the presence of lymphovascular invasion compared to patients with lower expression of $K L \gamma$. Our results suggest that $K L \gamma$ plays an important role in tumor invasion and progression and these results may lead to the development of new therapies and diagnostic methods for UCB.
\end{abstract}

\section{INTRODUCTION}

Urothelial carcinoma of the bladder (UCB) is one of the most important health issues worldwide. In Japan, $\mathrm{UCB}$ is the eighth most common malignancy in men [1]. Approximately $70 \%$ of UCBs are diagnosed as nonmuscle invasive bladder cancer (NMIBC) [2]. Although cancer-specific survival of patients with category Ta UCB is favorable, T1 NMIBC has the potential to progress to muscle invasive bladder cancer (MIBC), even with initial treatment including transurethral resection of bladder tumor (TURBT) and intravesical treatment. One of the biggest issues is that T1 UCB can be fatal, resulting from local progression or metastatic disease [3]. On the other hand, approximately $30 \%$ of UCBs are diagnosed as MIBC [4]. In spite of treatments, including radical cystectomy with or without neoadjuvant or adjuvant cisplatin-based chemotherapy, cancer-specific survival of patients with MIBC is not satisfactory [5]. With regard to advanced or metastatic $\mathrm{UCB}$, mortality has remained unchanged for the last 30 years and the cancer-specific survival of patients with advanced or metastatic UCB is poor, 
despite treatment using cisplatin-based chemotherapy [6]. Therefore, the development of novel diagnostic and therapeutic targets is an important and urgent matter.

Gamma-Klotho (KL $\gamma)$, also known as lactase-like protein, belongs to the glycosyl hydrolase 1 family and is a single-pass membrane protein containing 567 amino acids. KL $\gamma$ also belongs to the Klotho subfamily [7]. The alpha-Klotho (KLa) gene was originally identified as an anti-aging gene and the beta-Klotho (KLb) gene encodes an amino acid sequence that is $41.2 \%$ identical to that of $\mathrm{KLa}[8,9]$. The Klotho family are co-factors of fibroblast growth factors (FGF) 19, FGF21, and FGF23, which regulate tissue-specific metabolic activity [10]. Recently, the association between cancer and KLa has been reported as a new biomarker for cancer [11]. Most of the reports have suggested that KLa plays the role of a tumor suppressor, including promotion of apoptosis and inhibition of transforming growth factor-b1 signaling, which is involved in the epithelial-to-mesenchymal transition (EMT) [12-16]. On the other hand, the role of $\mathrm{KLb}$ in cancer prognosis is still controversial [17-19]. Our previous report suggested that high expression of KL $\beta$ was an independent predictive factor for short progressionfree survival of NMIBC and treatment with exogenous $\mathrm{KLb}$ increased proliferation, migration, transendothelial migration, and anchorage-independent growth in vitro [20]. With regard to $K L \gamma$, there are fewer reports about the association between KL $\gamma$ and cancer. Previous reports showed that KL $\gamma$ has an important role in the cell proliferation ability of colon cancer and the expression level of $\mathrm{KL} \gamma$ was associated with prognosis in triple negative breast cancer $[21,22]$. In the present study, we focused on the clinical significance of KL $\gamma$, which could be a regulator of cancer progression for UCB.

\section{RESULTS}

\section{KL $\gamma$ promotes tumor growth and tumor invasiveness of urothelial cancer cells}

To check the expression level of KL $\gamma$ in the three urothelial cancer cell lines, RT-PCR analysis was performed. All cell lines expressed endogenous $\mathrm{KL} \gamma$ mRNA (Figure 1A). Exogenous $\mathrm{KL} \gamma$ treatment at a concentration of $10 \mathrm{ng} / \mathrm{mL}$ promoted urothelial cancer cell proliferation by approximately $110 \%$ in MGH-U3 and UM-UC-3 cells ( $P=0.049$ and 0.046 , respectively). In the remaining conditions, no effect was observed (Figure 1B). With regard to the Matrigel invasion assay, exogenous KL $\gamma$ treatment enhanced invasiveness ability in MGH-U3, J82, and UM-UC-3 cells $(P=0.015,0.014$, and 0.011 , respectively; Figure 1C).

Figure 1D shows representative images of cell migration with or without exogenous KL $\gamma$ by the scratch wound healing assay. The result also revealed that exogenous $\mathrm{KL} \gamma$ treatment enhanced migration ability in
MGH-U3, J82, and UM-UC-3 cells $(P=0.047,0.004$, and 0.006 , respectively; Figure 1E). These results suggest that treatment with KL $\gamma$ enhanced the cells' ability to proliferate, invade, and migrate in vitro.

\section{KL $\gamma$ treatment enhances colony formation potential and anchorage-independent growth}

Colony formation ability was enhanced in J82 cells treated with exogenous $\operatorname{KL} \gamma(P=0.014$; Figure 2A). Cells were suspended in soft agar and incubated with or without $50 \mathrm{ng} / \mathrm{mL} \mathrm{KL} \gamma$. The number of colonies was counted one week after seeding. Evaluation on day 7 showed a notable increase in the colony formation ability of cells treated with KL $\gamma$ in MGH-U3, J82, and UM-UC-3 cells ( $P$ $=0.012,0.020$, and 0.011, respectively; Figure 2B). The treatment with KL $\gamma$ enhanced colony formation ability and anchorage-independent growth capability in vitro.

\section{KL $\gamma$ siRNA treatment inhibits tumor growth in vivo}

Figure 3A shows a schematic representation of the in vivo study. In the in vitro study, we confirmed by RTPCR analysis that transfection with $\mathrm{KL} \gamma$ siRNA knocked down the expression level of KL $\gamma$ mRNA in UM-UC-3 cells (Figure 3B). In the in vivo study, the treatments were well tolerated with no appreciable toxicity, including for body weight loss. Figure 3C shows representative images of xenografts in each group at the time of harvest. Xenografts of mice treated with KL $\gamma$ siRNA were the smallest tumors among the three groups. Significant tumor weight loss was observed in mice treated with KL $\gamma$ siRNA compared with the no treatment group (Figure 3D). The tumor growth rate during the treatment was significantly lower in mice treated with KL $\gamma$ siRNA compared with the no treatment group (Figure 3E).

\section{KL $\gamma$ siRNA treatment promotes EMT of bladder cancer cells}

Figure 4A shows representative images of xenograft tumors stained with each marker in each group. In the IHC analysis, xenografts of mice treated with KL $\gamma$ siRNA showed significantly lower expression of KL $\gamma$ compared with those of mice with no treatment $(P=0.0045$; Supplementary Figure 1A). Xenografts of mice treated with KL $\gamma$ siRNA showed significantly lower expression of Ki67 and an increase in apoptotic cells compared with those of mice with no treatment $(P=0.0050$, Supplementary Figure 1B; $P=0.0063$, Supplementary Figure 1C, respectively). Xenografts of mice treated with KL $\gamma$ siRNA also showed significantly higher expression of E-cadherin compared with that of mice with no treatment $(P=0.0099$; Supplementary Figure 1D). The higher expression level of $\mathrm{KL} \gamma$ was significantly correlated 

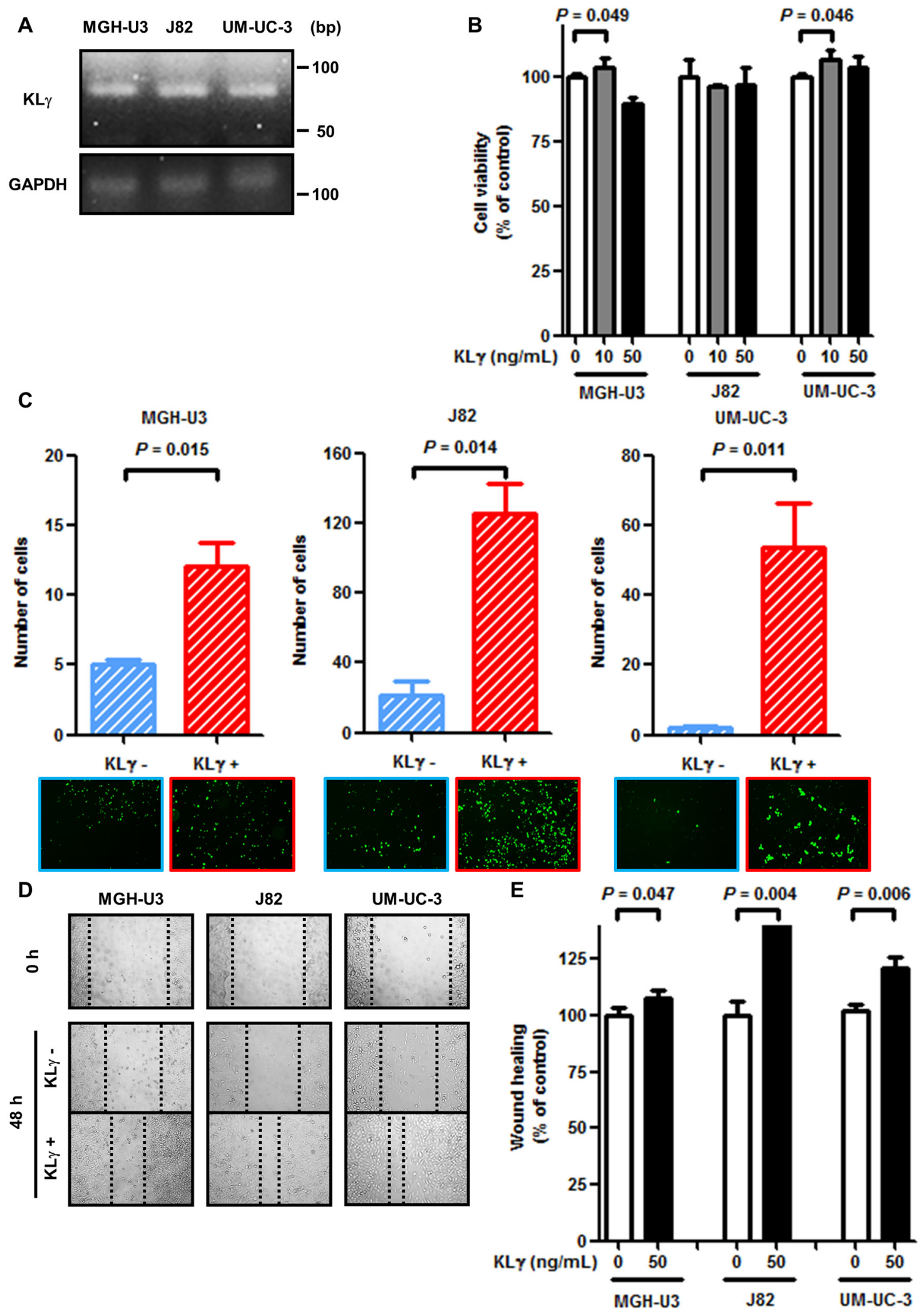

Figure 1: (A) MGH-U3, J82, and UM-UC-3 cells express KL $\gamma$ RNA. (B) In the viability assay, treatment with $10 \mathrm{ng} / \mathrm{mL}$ exogenous KL $\gamma$ increased the proliferation ability of MGH-U3 and UM-UC-3. (C) In the Matrigel invasion assay, treatment with exogenous KL $\gamma$ increased the invasive ability of all three cell lines. (D) Representative images of wound healing assay for each cell line. After $48 \mathrm{~h}$, migration ability was evaluated in each cell line. (E) In the wound healing assay, treatment with exogenous KL $\gamma$ increased the migration ability of all three cell lines. 
with higher expression of Ki67 and lower expression of TUNEL and E-cadherin $(P=0.0023, P=0.025$, and $P$ $=0.0016$, respectively; Table 1$)$. To confirm the effect of treatment with KL $\gamma$ siRNA, total RNA and cDNA was prepared from xenograft tumors and RT-PCR analysis was performed. KL $\gamma$ mRNA level decreased in xenografts of mice treated with KL $\gamma$ siRNA (Figure 4B). In addition, to investigate the involvement of EMT, the ERK1/2 pathway, and the Akt pathway, western blot analysis was performed. The concentration of E-cadherin increased in xenografts of mice treated with KL $\gamma$ siRNA and the concentrations of $\mathrm{N}$-cadherin and vimentin were decreased in this group.
Phosphorylation levels of AKT and ERK1/2 were not affected significantly by the transfection of KLg siRNA (Figure 4C).

\section{The association of KLy expression with clinicopathological variables in human bladder cancer}

To investigate the association between the expression levels of KL $\gamma$ in bladder tumor tissues and clinicopathological variables, IHC analysis for KL $\gamma$ expression was performed. Figure 5A shows
A
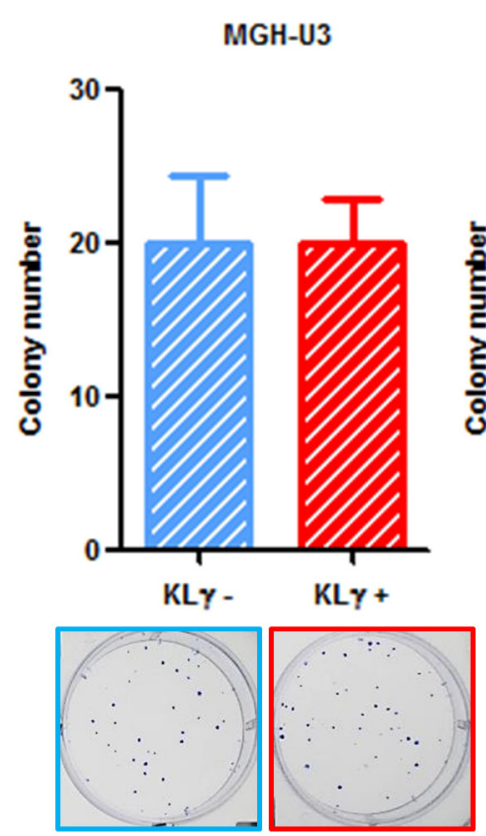

B

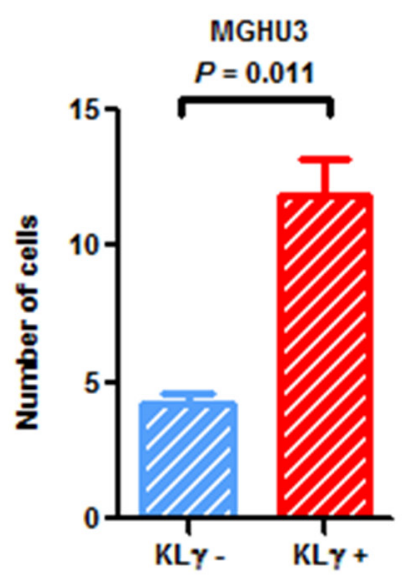

\section{Clonogenic assay}

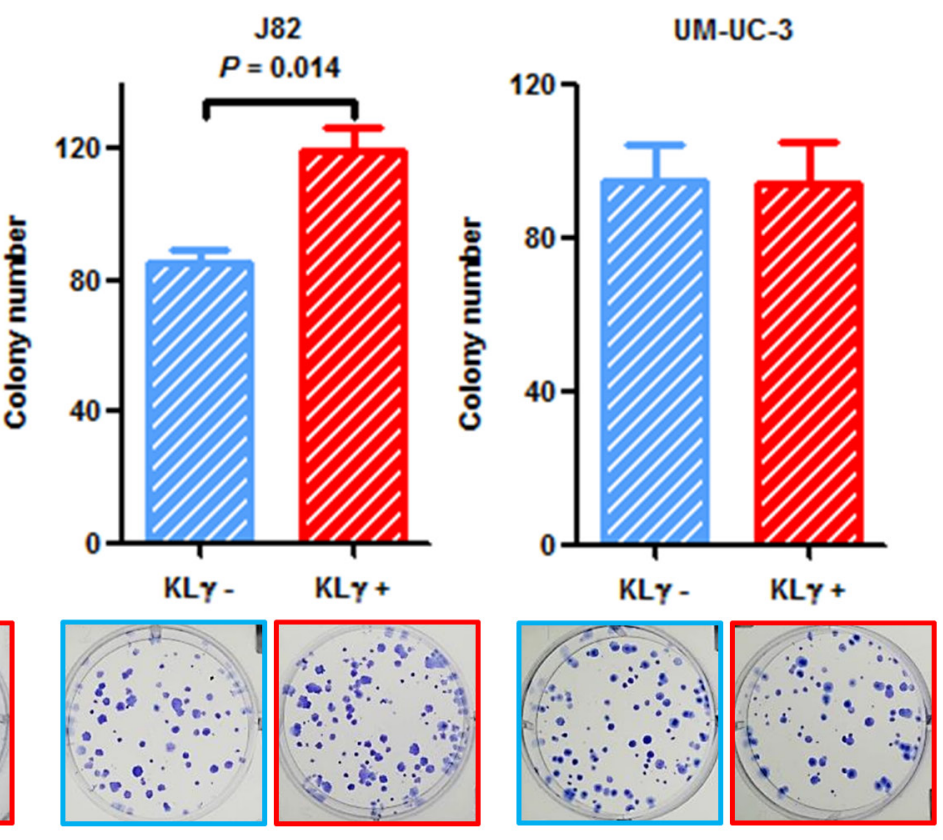

Soft agar colony formation assay

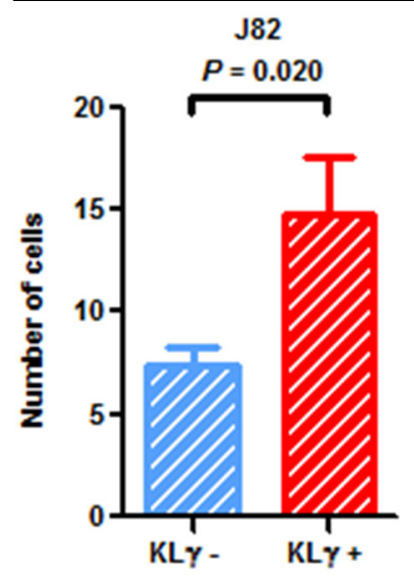

Figure 2: (A) In the clonogenic assay, treatment with exogenous KL $\gamma$ increased colony formation ability in J82. (B) Soft agar assays with or without treatment with exogenous KL $\gamma$ in three human urothelial carcinoma cell lines. The results showed that treatment with exogenous KL $\gamma$ increased the anchorage-independent growth capability of all the three cell lines. 
representative images of weak, intermediate, and strong expression of KL $\gamma$. KL $\gamma$ expression was higher in MIBC than that in NMIBC $(P=0.0002$; Figure 5B). Table 2 shows the clinicopathological backgrounds of a cohort of 151 NMIBC and 54 MIBC patients and comparisons of the variables with high and low KL $\gamma$ expression. The pathological data, such as tumor category, tumor grade, and lymphovascular invasion (LVI), were significantly different between patients with low and high KL $\gamma$ expression. The preoperative status including performance status and comorbidity were not correlated with the KL $\gamma$ expression. Thirty-one patients out of 205 died during the follow-up period and there were no association between cause of death and KL $\gamma$ expression.
The expression level of KL $\gamma$ is associated with progression-free survival of patients with NMIBC

Of the 205 patients, $21(10.2 \%)$ died of UCB at a median of 50 months after initial TURBT. Of those 21 patients, 8 patients were diagnosed as NMIBC primarily and progressed to MIBC. The remaining 13 patients were diagnosed as $\mathrm{MIBC}$ primarily, underwent radical cystectomy, and then had a recurrence in lymph node, lung, or bone. Of the 151 NMIBC patients, 53 (35.1\%) had an intravesical recurrence at median 35.5 months after initial TURBT and 18 (11.9\%) progressed to MIBC at median 52.0 months after initial TURBT. With regard to

A
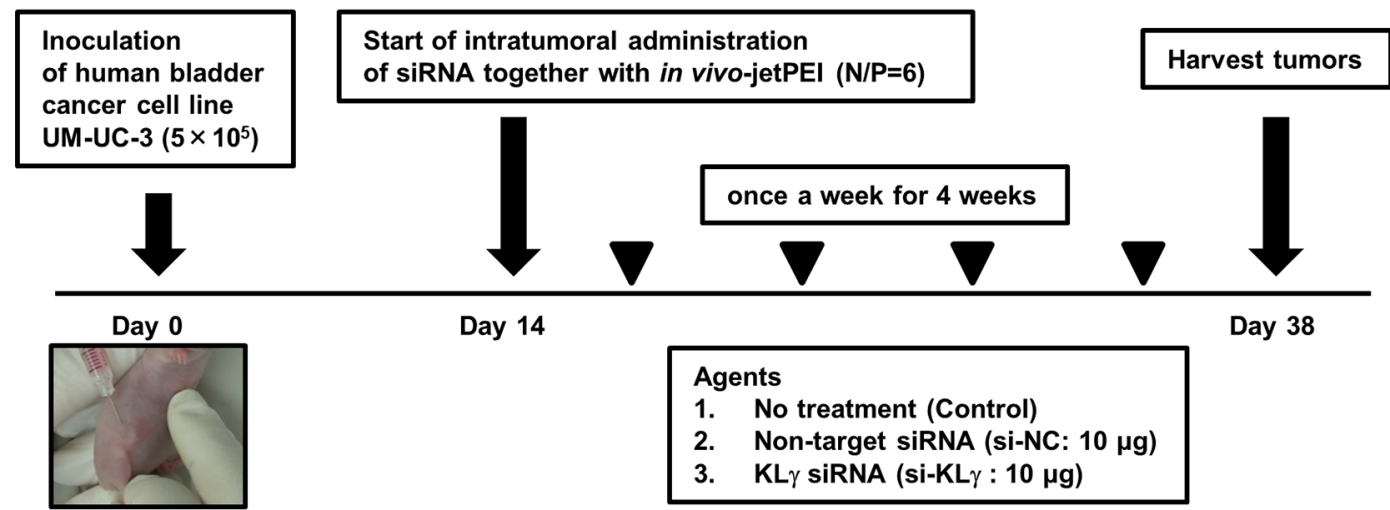

B

C
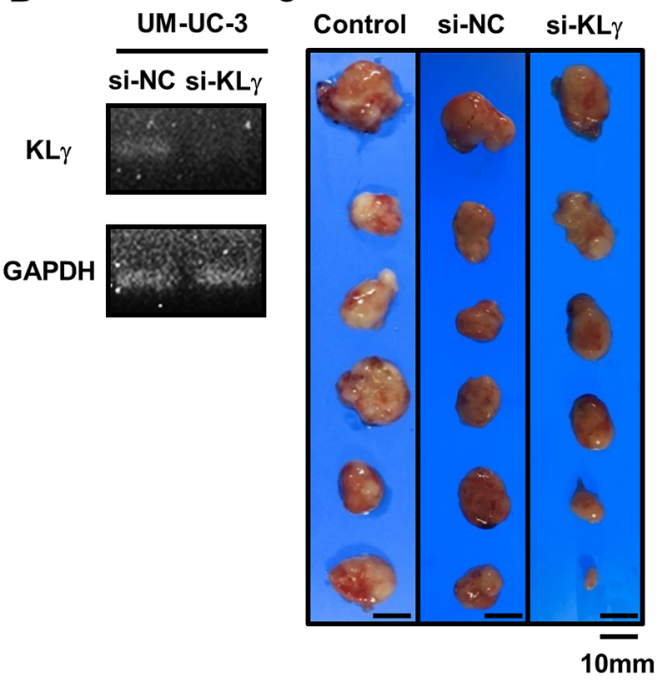

Day 38

\section{Agents}

1. No treatment (Control)

2. Non-target siRNA (si-NC: $10 \mu \mathrm{g}$ )

3. $K L \gamma$ SiRNA (si-KL $\gamma: 10 \mu g)$

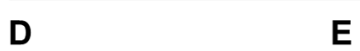

D

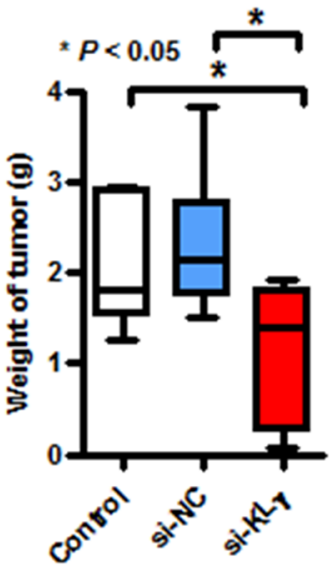

\section{E}

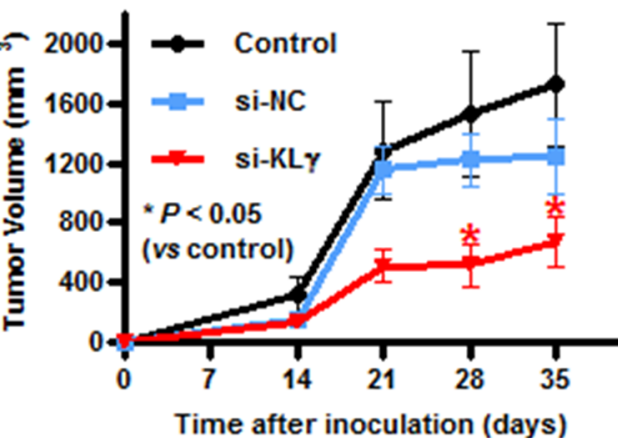

Type of treatment

Figure 3: (A) Schematic diagram illustrating the study workflow. Mice were injected with UM-UC-3 cells $\left(5 \times 10^{5} /\right.$ tumor $)$ together with Matrigel. Two weeks after inoculation, mice were randomly divided into three groups ( $\mathrm{n}=6$ per group; control (no treatment), negative control siRNA, and human KL $\gamma$ siRNA). Then, mice were treated once a week for 4 weeks. Three days after the last treatment, mice were euthanized and xenografts were harvested. (B) The treatment with KL $\gamma$ siRNA suppressed the expression levels of KL $\gamma$ mRNA in UMUC-3, as measured by RT-PCR analysis. (C) The resected xenografts from treatment group were photographed. (D) Intratumoral treatment with KL $\gamma$ siRNA caused significant resected xenograft weight loss compared to both the control group and the group of mice treated with negative control siRNA (Mann-Whitney $U$ test; $*=\mathrm{P}<0.05$ ). (E) Tumor growth rate during treatment was significantly lower in mice treated with KL $\gamma$ siRNA compared to both the control group and the group of mice treated with negative control siRNA (Mann-Whitney $U$ test; * $=\mathrm{P}<0.05)$. 
the intravesical recurrence- and progression-free survival in patients with high or low KL $\gamma$ expression, intravesical recurrence was tended to be more in patients with high KL $\gamma$ expression and intravesical progression significantly increased in patients with high KL $\gamma$ expression $(P=0.067$, Figure $5 \mathrm{C} ; P=0.013$, Figure $5 \mathrm{D}$, respectively). In contrast, of the 54 MIBC patients, $20(37.0 \%)$ had a recurrence at median 26.0 months after radical cyctectomy, 10 (18.5\%) died of UCB at median 46.5 months after radical cyctectomy, and $8(14.8 \%)$ died of other causes, such as lung cancer, pneumonia, and chronic kidney disease, at median 54.0 months after radical cyctectomy. With regard to the recurrence-free, disease-specific, and overall survival in patients with high or low KL $\gamma$ expression, there was no significant difference between the two groups $(P$ $=0.069$, Figure 5E; $P=0.84$, Figure 5F; $P=0.82$, Figure $5 \mathrm{G}$, respectively).

Table 3 shows the univariate and multivariate analysis of prognostic factors for the intravesical progression-free survival in NMIBC patients. The univariate analysis revealed that tumor grade, infiltration (INF) pattern, the presence of carcinoma in situ, the

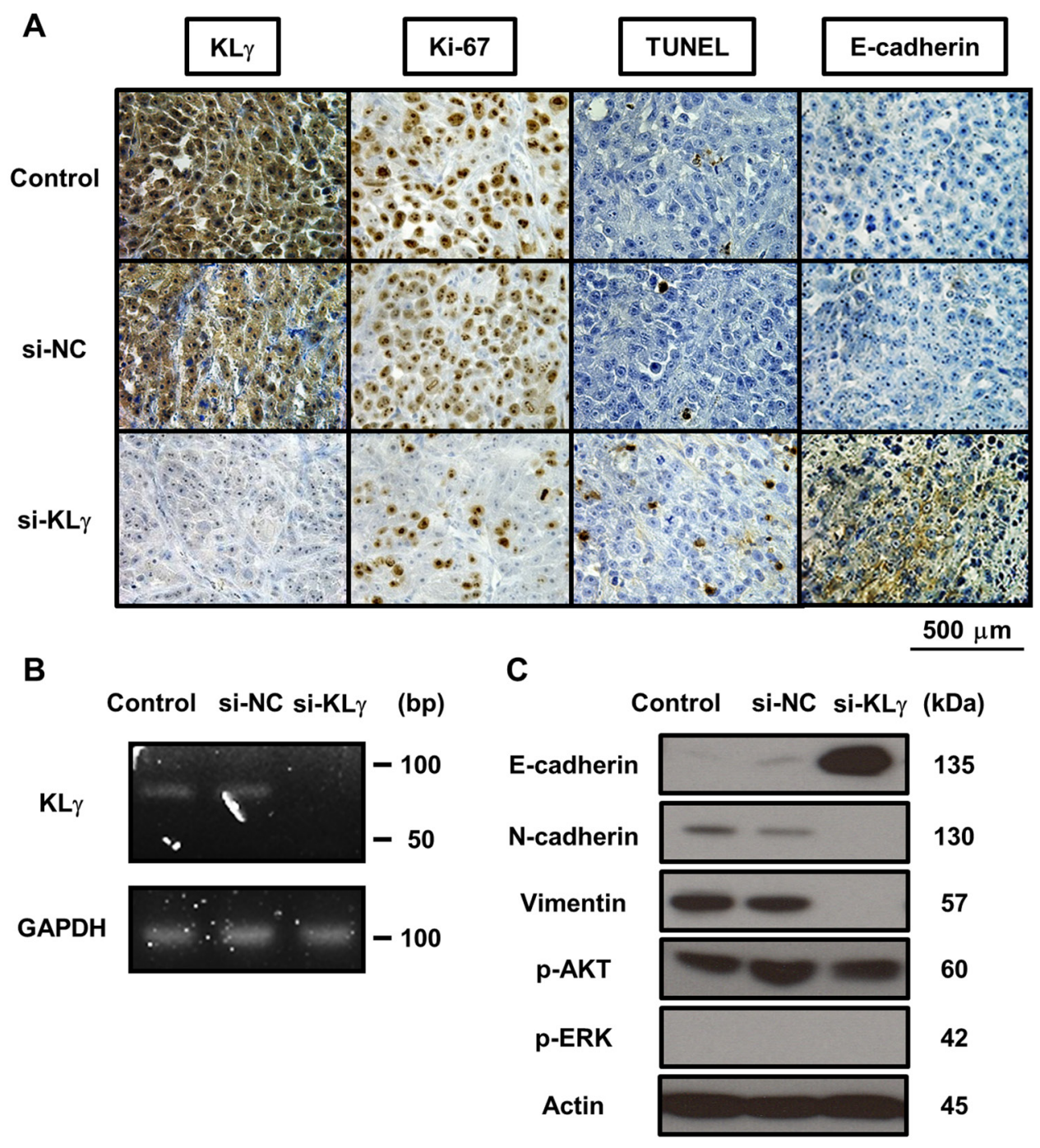

Figure 4: (A) Representative images of resected xenografts from each treatment group stained with four immunological markers. The expression levels of KL $\gamma$, Ki-67, TUNEL, and E-cadherin are noted. Expression levels of each marker in tumors of mice treated with KL $\gamma$ siRNA compared to both the control group and the group of mice treated with negative control siRNA. The expression levels of KL $\gamma$ and Ki-67 decreased in tumors of mice treated with KL $\gamma$ siRNA. The expression levels of TUNEL and E-cadherin increased in tumors of mice treated with KL $\gamma$ siRNA. (B) Treatment with KL $\gamma$ siRNA suppressed the expression levels of KL $\gamma$ mRNA in tumors of mice treated with KL $\gamma$ siRNA, as measured by RT-PCR analysis. (C) Western blot analysis of protein extracted from resected xenografts in each treatment group. The expression levels of E-cadherin, N-cadherin, vimentin, phospho-AKT, phospho-ERK1/2, and actin (as a control) were noted. The expression level of E-cadherin was increased in tumors of mice treated with KL $\gamma$ siRNA. The expression levels of N-cadherin and vimentin decreased in tumors of mice treated with KL $\gamma$ siRNA. 
Table 1: Correlation between the expression level of KL $\gamma$ and the expression levels of Ki-67/TUNEL/E-cadherin, as determined by IHC in the in vivo study

\begin{tabular}{lcc}
\hline & Spearman $\mathbf{r}$ & $\boldsymbol{P}$ value \\
\hline Ki67 & 0.79 & 0.0023 \\
TUNEL & -0.64 & 0.025 \\
E-cadherin & -0.81 & 0.0016 \\
\hline
\end{tabular}

There was significant correlation between the expression level of KL $\gamma$ and the others.

Abbreviations: KL $\gamma$, gamma-Klotho; TUNEL, terminal deoxynucleotidyl transferase-mediated dUTP nick end labeling;

IHC, immunohistochemistry.

presence of LVI, and high KL $\gamma$ expression was the predictive factors for the intravesical progression (hazards ratio $[\mathrm{HR}]=3.0,95 \%$ confidence interval $[\mathrm{CI}] 1.0-9.1$; $P=0.05 ; \mathrm{HR}=6.6,95 \%$ CI $2.5-17.4, P<0.0001 ; \mathrm{HR}=$ $2.8,95 \%$ CI $1.1-7.5, P=0.034$; HR $=3.2,95 \%$ CI 1.3 $7.9, P=0.014 ; \mathrm{HR}=3.6,95 \%$ CI $1.2-10.9, P=0.013$, respectively). The multivariate analysis showed that INF and high KL $\gamma$ expression were independent prognostic factors for the intravesical progression-free survival in NMIBC patients. $(\mathrm{HR}=7.8,95 \%$ CI 1.3-44.9; $P=0.022$; $\mathrm{HR}=4.3,95 \%$ CI $1.2-10.9 ; P=0.025)$.

\section{DISCUSSION}

Our previous report suggests that KLb acts as a tumor promoter in human UCB and that KLa does not have a significant role as a tumor suppressor or promoter in human UCB [20]. We hypothesized that KLb plays a role as a tumor promoter, together with FGF21 or FGF19. Although additional experiments were performed, we could not demonstrate an association between KLb and the FGF receptor (FGFR) pathways involving FGF21 and FGF19. Therefore, we focused on another co-factor of FGFs, named KL $\gamma$, which predominantly acts with FGF19 and FGFR4 [23]. FGF/FGFR signaling plays an important role in tumor progression, including tumor proliferation, cell differentiation, and angiogenesis [24-26]. Thus, we hypothesized that $K L \gamma$ had a role as a tumor promoter in UCB through the activation of FGF/FGFR signaling.

The present study revealed that in an in vitro study, treatment with exogenous KL $\gamma$ increased the ability of invasion, migration, colony formation, and anchorageindependent growth. With regard to cell viability assay, dose dependent manner was not observed. Although the reason is not clear, the solvent of recombinant-KL $\gamma$ protein might contain harmful materials. In the in vivo study, tumor growth was significantly suppressed by treatment with KL $\gamma$ siRNA, suggesting that KL $\gamma$ could act as a tumor promoter. The present study also showed that patients with high KL $\gamma$ expression had a significantly higher stage and grade of UCB and a higher risk rate of the intravesical progression. In multivariate analysis, high $\mathrm{KL} \gamma$ expression was an independent prognostic factor for progression-free survival in patients with NMIBC. Although the result of in vitro study suggested that high expression level of KL $\gamma$ affected INF, there was no significant difference between patients with high expression level of KL $\gamma$ and those with low expression level of KL $\gamma$. This might be because the number of patients was apparently small.

At present, most of our understanding regarding the functional roles of FGFRs and their signaling pathways has been derived mainly from the study of FGFR1, FGFR2, and FGFR3. There are only limited reports about FGFR4. Recently, there have been several reports about the association between FGF19 and FGFR4 signaling and cancer prognosis. In hepatocellular carcinoma (HCC), the expression level of FGF19 in HCC tissues was significantly higher compared with noncancerous liver tissues and tumor FGF19 mRNA expression was an independent prognostic factor for mortality. In addition, FGF19 and FGFR4 signaling had an effect on HCC resistance to sorafenib therapy through the inhibition of reactive oxygen species generation and apoptosis [27, 28]. Tiong et al. suggested that FGF19 and FGFR4 signaling mediated the viability of cancer cells through activation of the PI3K/AKT pathway in breast cancer [29]. Hu et $a l$. also suggested that patients with high expression of both FGF19 and FGFR4 had significantly poor prognoses for ovarian cancer and that FGF19 and FGFR4 signaling could promote ovarian cancer proliferation and invasion through the AKT-MAPK signaling pathway [30]. In prostate cancer, FGF19/FGFR signaling promotes cancer progression along with the presence of KLa and/or KLb as co-factors [18]. There have been no reports about the oncological function of FGF19/FGFR4 signaling in UCB.

In the in vivo study, treatment with KL $\gamma$ siRNA suppressed tumor growth rate, indicating that KL $\gamma$ has some role in promoting tumor cell growth, including enhancement of the cell cycle and inhibition of apoptosis. Although we expected that this phenomenon was involved in the activation of the ERK1/2 signaling pathway or the AKT signaling pathway, we could not determine a direct 

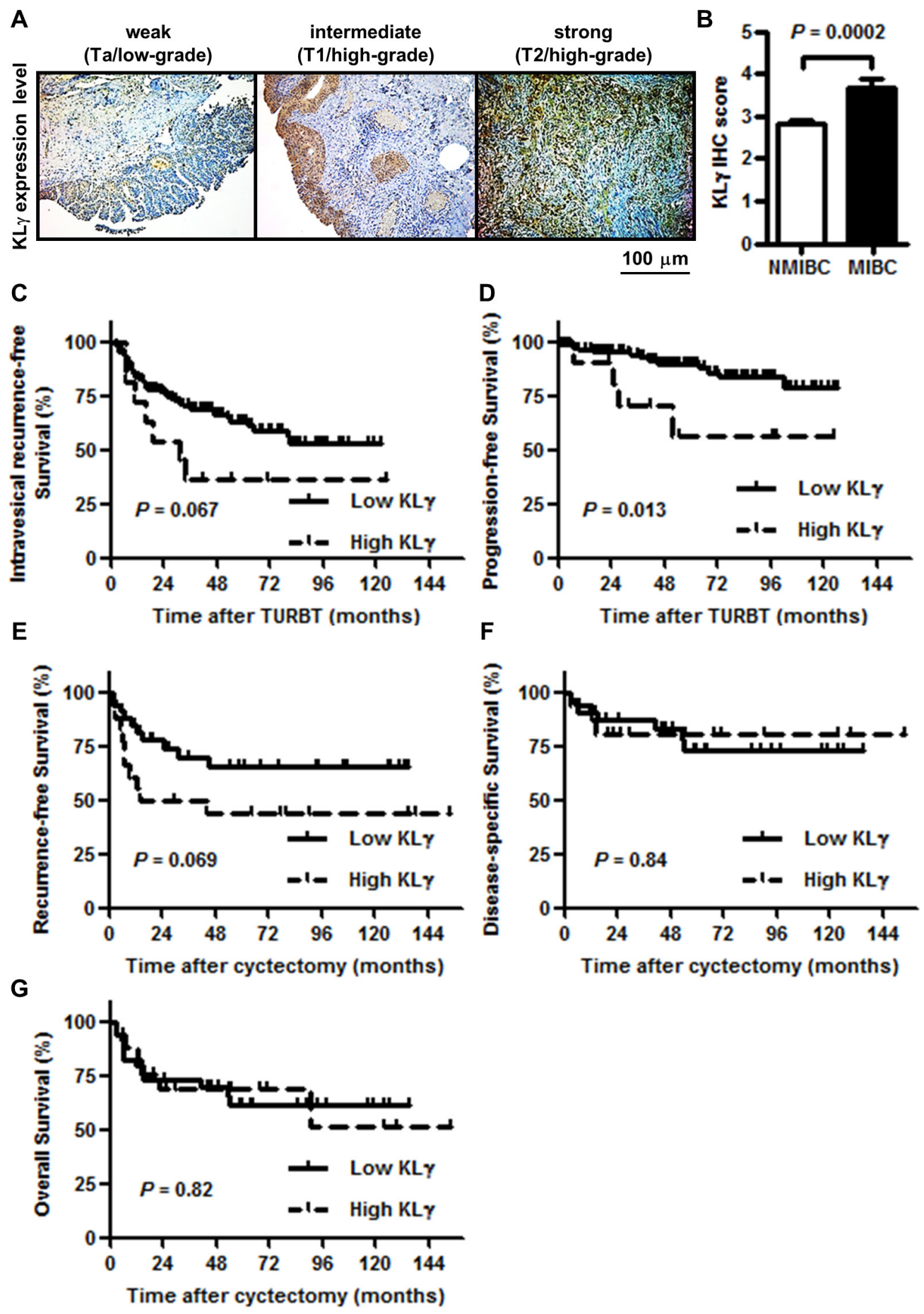

Figure 5: (A) KL $\gamma$ was expressed in urothelial carcinomas of the bladder and the expression level gradually increased as tumors progressed to higher stages and grades. Scale bars, $100 \mu \mathrm{m}$. (B) Quantification of KL $\gamma$ expression level in non-muscle invasive bladder cancer (NMIBC) versus muscle invasive bladder cancer (MIBC). The expression level of KL $\gamma$ was significantly higher in MIBC than NMIBC. (C) Although patients with the high KL $\gamma$ expression were tended to have the intravesical recurrence in non-muscle invasive bladder cancer, there was no significant difference. (D) Patients with the high KL $\gamma$ expression significantly progressed to muscle invasive bladder cancer compared to patients with the low KL $\gamma$ expression in non-muscle invasive bladder cancer. (E) Although patients with the high KL $\gamma$ expression were tended to have the recurrence in muscle invasive bladder, there was no significant difference. (F) There was no significant difference of disease-specific survival between patients with low KL $\gamma$ expression and those with high KL $\gamma$ expression in muscle invasive bladder cancer. (G) There was no significant difference of overall survival between patients with low KL $\gamma$ expression and those with high KL $\gamma$ expression in muscle invasive bladder cancer. 
Table 2: Patients' clinicopathological background

\begin{tabular}{|c|c|c|c|c|}
\hline \multirow{2}{*}{ Variables } & \multirow{2}{*}{ Number of patients } & \multicolumn{2}{|c|}{ KLy expression } & \multirow{2}{*}{$P$ value } \\
\hline & & Low & High & \\
\hline Total & 205 & 176 & 29 & \\
\hline Gender & & & & $0.78^{\dagger}$ \\
\hline Male & 173 & 149 & 24 & \\
\hline Female & 32 & 27 & 5 & \\
\hline Age (at initial TURBT) & & & & $0.26 *$ \\
\hline Median (IQR) & $71(34-94)$ & $71(34-93)$ & $72(52-83)$ & \\
\hline ECOG-PS (at initial TURBT) & & & & $0.23^{\dagger}$ \\
\hline 0 & 190 & 165 & 25 & \\
\hline 1 & 9 & 6 & 3 & \\
\hline 2 & 6 & 5 & 1 & \\
\hline $\begin{array}{l}\text { Charlson comorbidity } \\
\text { index }\end{array}$ & & & & $0.83^{\dagger}$ \\
\hline 0 & 138 & 119 & 19 & \\
\hline$\geq 1$ & 67 & 57 & 10 & \\
\hline Follow up (months) & & & & $0.62 *$ \\
\hline Median (IQR) & $52(3-154)$ & $52(3-135)$ & $53(3-154)$ & \\
\hline T category & & & & $0.0003^{\dagger}$ \\
\hline $\mathrm{Ta}$ & 65 & 61 & 4 & \\
\hline $\mathrm{T} 1$ & 72 & 67 & 5 & \\
\hline Tis & 14 & 12 & 2 & \\
\hline $\mathrm{T} 2$ & 29 & 20 & 9 & \\
\hline $\mathrm{T} 3$ & 18 & 12 & 6 & \\
\hline $\mathrm{T} 4$ & 7 & 4 & 3 & \\
\hline Tumor Grade (2004 edition) & & & & $0.0049^{\dagger}$ \\
\hline High & 137 & 111 & 26 & \\
\hline Low & 68 & 65 & 3 & \\
\hline Tumor Grade (1973 edition) & & & & $0.0010^{\dagger}$ \\
\hline G1 & 21 & 19 & 2 & \\
\hline $\mathrm{G} 2$ & 86 & 82 & 4 & \\
\hline G3 & 98 & 75 & 23 & \\
\hline INF & & & & $0.46^{\dagger}$ \\
\hline$a / b$ & 165 & 143 & 22 & \\
\hline $\mathrm{c}$ & 40 & 33 & 7 & \\
\hline Concomitant CIS with $\mathrm{pTa} / 1 / 2 / 3 / 4(\mathrm{n}=191)$ & & & & $0.51^{\dagger}$ \\
\hline Yes & 63 & 56 & 7 & \\
\hline No & 128 & 108 & 20 & \\
\hline LVI with $\mathrm{pT} 1 / 2 / 3 / 4(\mathrm{n}=126)$ & & & & $0.039^{\dagger}$ \\
\hline Yes & 62 & 46 & 16 & \\
\hline No & 64 & 57 & 7 & \\
\hline
\end{tabular}




\begin{tabular}{|c|c|c|c|c|c|}
\hline \multirow{2}{*}{ Variables } & & \multirow{2}{*}{ Number of patients } & \multicolumn{2}{|c|}{ KLy expression } & \multirow{2}{*}{$P$ value } \\
\hline & & & Low & High & \\
\hline \multirow[t]{7}{*}{ Cause of death } & & & & & $0.41^{\dagger}$ \\
\hline & Bladder cancer & 21 & 16 & 5 & \\
\hline & Another cancer & 2 & 1 & 1 & \\
\hline & Pneumonia & 3 & 3 & 0 & \\
\hline & Peritonitis & 1 & 1 & 0 & \\
\hline & $\begin{array}{l}\text { Chronic renal } \\
\text { failure }\end{array}$ & 1 & 0 & 1 & \\
\hline & Unknown & 3 & 2 & 1 & \\
\hline
\end{tabular}

Patients with high KL $\gamma$ expression showed high stage, high grade cancer and the presence of lymphovascular invasion. Abbreviations: KL $\gamma$, gamma-Klotho; TURBT, transurethral resection of bladder tumor; IQR, interquartile range; ECOG-PS, Eastern Cooperative Oncology Group performance status; INF, infiltration; CIS, carcinoma in situ; LVI, lymphovascular invasion; ${ }^{\dagger}$ Chi-square test or Fisher’s exact test; ${ }^{\ddagger}$ Mann-Whitney $U$ test.

Table 3: Cox regression analysis of prognostic factors for overall survival

\begin{tabular}{|c|c|c|c|c|c|c|c|}
\hline \multirow{2}{*}{ Variables } & & \multicolumn{3}{|c|}{ Univariate analysis } & \multicolumn{3}{|c|}{ Multivariate analysis } \\
\hline & & HR & $95 \%$ CI & $P$ value & HR & $95 \% \mathrm{CI}$ & $P$ value \\
\hline \multirow[t]{3}{*}{ Gender } & & & & 0.39 & & & \\
\hline & Male & 1 & & & & & \\
\hline & Female & 1.7 & $0.5-6.0$ & & & & \\
\hline \multirow[t]{3}{*}{ Age } & & & & 0.27 & & & \\
\hline & $<70$ & 1 & & & & & \\
\hline & $\geq 70$ & 1.7 & $0.7-4.6$ & & & & \\
\hline \multirow[t]{4}{*}{$\mathrm{T}$ category } & & & & 0.099 & & & \\
\hline & $\mathrm{Ta}$ & 1 & & & & & \\
\hline & $\mathrm{T} 1$ & 2.5 & $0.8-7.8$ & & & & \\
\hline & Tis & 4.5 & $1.1-18.1$ & & & & \\
\hline \multirow[t]{3}{*}{ Tumor Grade } & & & & 0.05 & & & 0.61 \\
\hline & Low & 1 & & & 1 & & \\
\hline & High & 3 & $1.0-9.1$ & & 0.58 & $0.07-4.8$ & \\
\hline \multirow[t]{3}{*}{ INF } & & & & $<0.0001$ & & & 0.022 \\
\hline & No & 1 & & & 1 & & \\
\hline & Yes & 6.6 & $2.5-17.4$ & & 7.8 & $1.3-44.9$ & \\
\hline \multirow[t]{3}{*}{ CIS } & & & & 0.034 & & & 0.45 \\
\hline & No & 1 & & & 1 & & \\
\hline & Yes & 2.8 & $1.1-7.5$ & & 1.8 & $0.4-8.3$ & \\
\hline \multirow[t]{3}{*}{ LVI } & & & & 0.014 & & & 0.59 \\
\hline & No & 1 & & & 1 & & \\
\hline & Yes & 3.2 & $1.3-7.9$ & & 1.7 & $0.3-10.4$ & \\
\hline \multirow[t]{3}{*}{ KL $\gamma$ expression } & & & & 0.013 & & & 0.025 \\
\hline & Low & 1 & & & 1 & & \\
\hline & High & 3.6 & $1.2-10.9$ & & 4.3 & $1.2-15.3$ & \\
\hline
\end{tabular}

The high expression level of KL $\gamma$ was not an independent poor prognostic factor.

Abbreviations: KL $\gamma, \gamma$-klotho; INF, infiltration; CIS, carcinoma in situ; LVI, lymphovascular invasion; HR, hazard ratio; CI, confidence interval. 
relationship between KL $\gamma$ and those signaling pathways. Previous reports suggested that FGF/FGFR signaling affects the ability of proliferation and apoptosis in tumor cells via the activation of the ERK1/2 or AKT signaling pathways [31, 32]. Kim et al. reported that KL $\gamma$ is an important factor for cell proliferation and that the presence of various KL members affects the degree of activation of signaling pathways in colon cancer [21]. Trošt et al. showed that, in patients with triple negative breast cancer, the expression level of KL $\gamma$ was high and correlates with poor progression, that KL $\gamma$ was a necessary factor for cell survival, and that depletion of KL $\gamma$ resulted in cell cycle arrest, apoptosis, and persistent activation of the ERK1/2 signaling pathway [22]. Therefore, we hypothesize that KL $\gamma$ plays a role in the promotion of bladder cancer and that the balance of existing KLs affects downstream signaling, including that of FGF and FGFR.

With regard to the epithelial-to-mesenchymal transition (EMT), there have been several reports indicating the association of KLs and FGF/FGFR signaling. KLa has a role in inhibiting TGF- $\beta 1$-induced EMT and FGF19/FGFR4 signaling induces EMT in cholangiocarcinoma. In HCC, FGF19/FGFR4 signaling enhances EMT via the GSK3 $\beta / \beta$-catenin signaling pathway $[14,33,34]$. Also with respect to UCB, EMT is involved in tumor progression and metastasis and expression levels of FGFRs are correlated with expression levels of EMT marker such as E-cadherin and vimentin [35-37]. Thus, we hypothesized that high expression of KL $\gamma$ promoted EMT in bladder cancer, resulting in poor prognosis. In the in vivo study, treatment with KL $\gamma$ siRNA suppressed a decrease in the expression of E-cadherin and enhanced the expression of $\mathrm{N}$-cadherin and vimentin. This result suggests that the depletion of KL $\gamma$ in bladder cancer leads to cadherin switching, resulting in the suppression of EMT. Although the mechanism for EMT induction is not clear, KL $\gamma$ might be correlated with the induction of EMT in bladder cancer. We speculate that the EMT related with

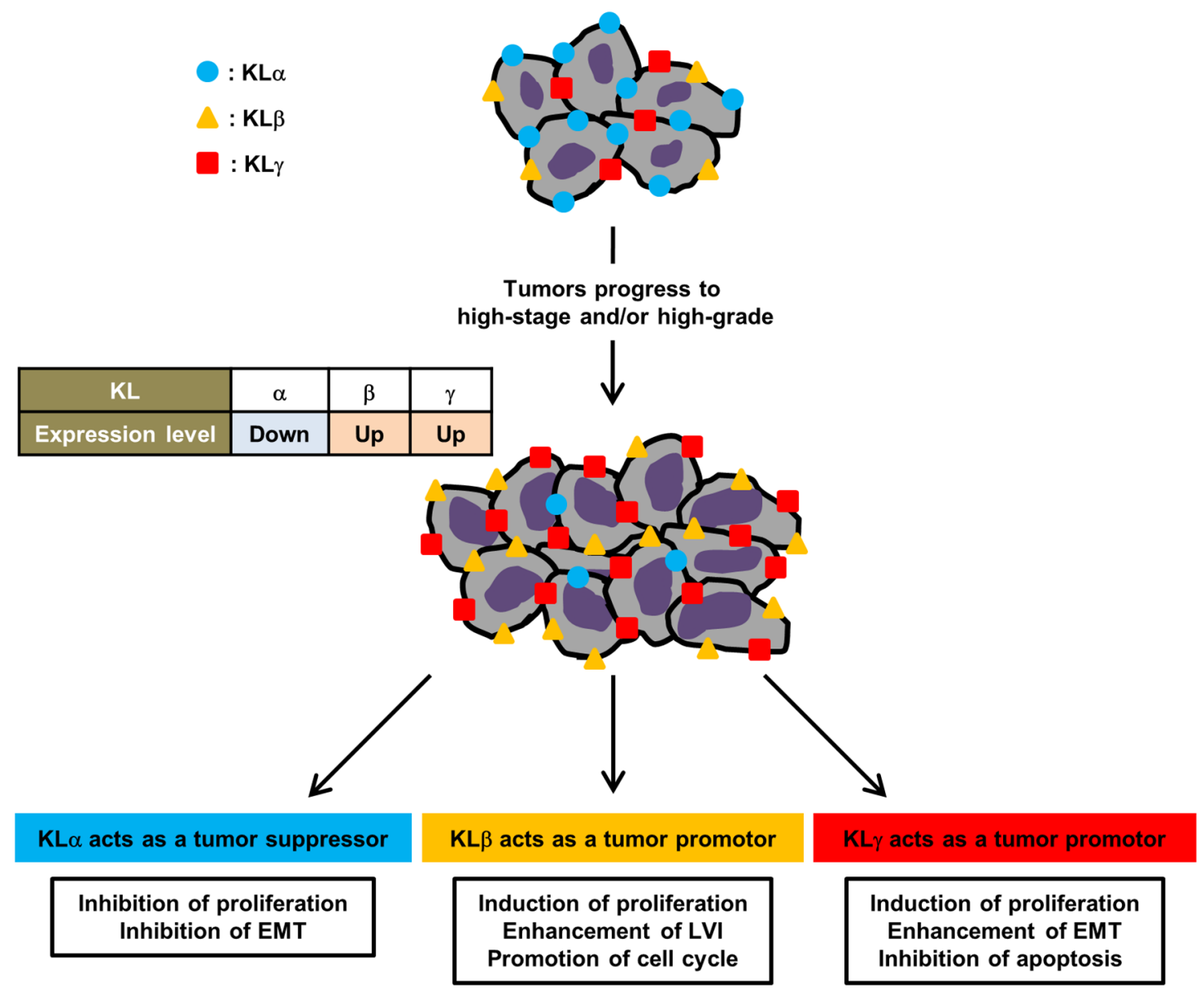

Figure 6: Roles of klotho family in bladder cancer. In urothelial carcinoma of the bladder, along with increase of tumor grade the expression level of KL $\alpha$ decrease and the expression levels of KL $\beta$ and KL $\gamma$ increase. KLs are orchestrating to affect cancer progression. KLa acts as a tumor suppressor mediated by inhibition of the IGF-1/insulin signaling pathway and EMT. KLb acts as a tumor promotor mediated by regulation of FGF4 signaling pathway, phosphorylation of ERK1/2 and FRS2. Similarly, KL $\gamma$ acts as a tumor promotor mediated by regulation of FGF4 signaling pathway, ERK1/2 pathway, and EMT. 
KL $\gamma$ is induced by FGF19/FGFR4 signaling because KL $\gamma$ is a co-factor of FGF19.

To our knowledge, the present study is the first report regarding the association between KL $\gamma$ and bladder cancer prognosis. The expression of KL $\gamma$ was higher in patients with higher stage, higher grade cancer, and presence of LVI compared to those patients with lower stage, lower grade cancer, and an absence of LVI. The expression level of KL $\gamma$ was an independent prognostic factor for the intaravesical progression in patients with NMIBC. In addition, in vitro study the treatment with exogenous KL $\gamma$ showed increase in tumor progression capability such as invasion, migration, and colony formation and in vivo study the treatment with KL $\gamma$ siRNA showed suppression of tumor growth. Therefore we believe that KL $\gamma$ acts as a promoter of UCB. Together with our previous study of $\mathrm{UCB}, \mathrm{KLa}, \mathrm{KLb}$, and $\mathrm{KL} \gamma$ may be correlated with tumor growth. Our results suggested that the KLa expression level decreased along with increase of tumor grade, contrary the KLb and KL $\gamma$ expression levels increased along with increase of tumor grade. KLa has tumor-suppressing roles on cell proliferation and survival, resulting from inhibition of the IGF-1/insulin signaling pathway and EMT. KLb and KL $\gamma$ act as a tumor promotor. KLb affects FGF4 signaling pathway, phosphorylation of ERK1/2 and FRS2, resulting in enhancement of cell proliferation or inhibition of cancer cell apoptosis. KL $\gamma$ also might affect FGF4 signaling pathway, ERK1/2 pathway and EMT, resulting in cancer prognosis. In addition, the KLs expression levels are correlated with each other and this status might affect cancer prognosis $(12,15,17,20-22)$. Figure 6 shows the association on roles of each KL in UCB.

This study has some limitations. Firstly, the direct relationship between KL $\gamma$ as a co-receptor of FGFR and FGF/FGFR signaling could not be elucidated in this study. We attempted to show the association between KLb and FGF/FGFR signaling in a previous study; however, human bladder cancer samples were not stained with anti-FGF and anti-FGFR antibodies. Further, experiments using natural carcinogenesis and a KL $\gamma$ knockdown mouse model of bladder cancer are needed to elucidate the involvement of KL $\gamma$ in bladder cancer. Secondly, cytokines involved in cell proliferation, apoptosis, and EMT were not evaluated in this study. Further, experiments are needed to reveal the association between $\mathrm{KL} \gamma$ and these mechanisms of tumorigenesis. Thirdly, there might be variations about tumor injection, tumor growth, and intratumoral administration. These variations might affect the results of in vivo study. Fourthly, although KL $\gamma$ was an independent prognostic factor for the intaravesical progression in patients with NMIBC, KL $\gamma$ was not a poor prognostic factor for patients with MIBC. We need to increase the number of patients to reveal the association between $\mathrm{KL} \gamma$ and UCB. Careful interpretation needs to be done in a confirmation study using clinicopathological data.
In conclusion, our findings suggested that KL $\gamma$ plays a pivotal role in the growth of human UCB. The expression level of KL $\gamma$ was associated with cell proliferation, apoptosis, and EMT, creating a milieu favorable to the survival and expansion of tumors. Improved knowledge about the actual involvement of KL $\gamma$, together with KLa and $\mathrm{KLb}$, is expected to facilitate the search for new therapies and diagnostic methods for UCB.

\section{MATERIALS AND METHODS}

\section{Cell lines and reagents}

The human urothelial carcinoma cell lines MGH-U3, J82, and UM-UC-3 were used in this study. MGH-U3 was a gift from Dr. H. LaRue (Laval University Cancer Research Centre, Quebec, Canada). J82 and UMUC-3 were purchased from the American Type Culture Collection (ATCC, Manassas, VA, USA). The cell lines were maintained in RPMI-1640 medium (Nacalai Tesque, Kyoto, Japan) supplemented with $10 \%$ fetal bovine serum (FBS; JRH, Tokyo, Japan) and $1 \%$ penicillin and streptomycin (Thermo Scientific, Yokohama, Japan) in a standard humidified incubator at $37^{\circ} \mathrm{C}$ in an atmosphere of $5 \% \mathrm{CO}_{2}$. Recombinant human $\mathrm{KL} \gamma$ protein was purchased from Abnova (H00197021-P01; Taipei, Taiwan) and diluted in sterile saline solution according to the manufacturer's instructions. Sterile phosphate-buffered saline (PBS) was used as a control.

\section{Quantitative reverse transcription-polymerase chain reaction (RT-PCR)}

Quantitative RT-PCR was performed to measure the expression levels of KL $\gamma$ RNA in each cell line and resected tumors. For in vitro study, cells were seeded in 6 -well plates at a density of $1 \times 10^{5}$ cells/well in growth medium and incubated for $24 \mathrm{~h}$. RNA was extracted using an RNeasy Mini kit (Qiagen, Valencia, CA, USA) according to the manufacturer's instructions. For the in vivo study, after homogenization of tumors, RNA was extracted using a QIAamp RNA Blood Mini kit (Qiagen, Valencia, CA, USA) according to the manufacturer's instructions. Conversion to cDNA was achieved using a High Capacity cDNA Reverse Transcription kit (Life Technologies, Carlsbad, CA, USA). Quantitative RTPCR was carried out using the cDNA, $0.2 \mu \mathrm{M}$ of each primer, and $10 \mu \mathrm{L}$ of AmpliTaq Gold ${ }^{\circledR}$ PCR Master Mix (Applied Biosystems, Foster City, CA, USA) under the following conditions: denaturation at $95^{\circ} \mathrm{C}$ for $10 \mathrm{~min}$; 40 cycles of denaturation at $95^{\circ} \mathrm{C}$ for $15 \mathrm{sec}$; annealing and a final extension at $60^{\circ} \mathrm{C}$ for $1 \mathrm{~min}$. PCR products were then electrophoresed in a $1.5 \%$ agarose gel and visualized by a transilluminator. Subsequent to verifying the mRNA expression of KL $\gamma$, semi-quantitative RT-PCR for this gene was performed in each cell line and resected tumors. 
Glyceraldehyde 3-phosphate dehydrogenase (GAPDH) was used as a control.

\section{Cell viability assays}

Cell proliferation assays were performed to examine the effects of the exogenous recombinant human KL $\gamma$. Cells were seeded in a 96-well plate at a density of 2,000 cells/well in serum-free medium, incubated for $24 \mathrm{~h}$, and treated with three different conditions of exogenous KL $\gamma$ $(0,10$, or $50 \mathrm{ng} / \mathrm{mL})$ for $48 \mathrm{~h}$ at $37^{\circ} \mathrm{C}$ in an atmosphere of $5 \% \mathrm{CO}_{2}$. Cell Counting Kit-8 (Dojindo, Kumamoto, Japan) was used to measure the number of viable cells according to the manufacturer's instructions.

\section{Matrigel invasion assay}

To evaluate whether cell migration ability would increase with exogenous $\mathrm{KL} \gamma$, the Matrigel invasion assay was performed using a FluoroBlok insert system. The insert membrane chambers were coated with $100 \mu \mathrm{L}$ of Matrigel (Corning Incorporated, Corning, NY, USA) and incubated at $37^{\circ} \mathrm{C}$ in an atmosphere of $5 \% \mathrm{CO}_{2}$. Cells were seeded in the upper chambers at a density of $2.5 \times 10^{4}$ cells/well in serum-free medium and incubated at $37^{\circ} \mathrm{C}$ in an atmosphere of $5 \% \mathrm{CO}_{2}$ with or without $50 \mathrm{ng} / \mathrm{mL} \mathrm{KL} \gamma$. After $48 \mathrm{~h}$ of incubation, non-invading cells in the upper chambers were removed, the invading cells in the lower chambers were stained with Calcein AM (Promokine, Heidelberg, Germany), and the cells were immediately examined under a fluorescence microscope (Leica DMI 4000B, Wetzlar, Germany).

\section{Wound healing assay}

To evaluate the effect of exogenous KL $\gamma$ on cell migration ability, the scratch wound healing assay was performed. Cells were seeded in a 12-well plate at a density of $5 \times 10^{4}$ cells/well and grown to approximately $90 \%$ confluency at $37^{\circ} \mathrm{C}$ in an atmosphere of $5 \% \mathrm{CO}_{2}$. Each plate was scratched with $10-100-\mu \mathrm{L}$ pipette tips, rinsed twice with $\mathrm{PBS}$, and then incubated in serumcontaining medium with or without $50 \mathrm{ng} / \mathrm{mL}$ KL $\gamma$. At 0 and $48 \mathrm{~h}$ incubation, the width of the wound was measured at four randomly selected points and the width of the wound at $0 \mathrm{~h}$ was compared with the width at $48 \mathrm{~h}$.

\section{Clonogenic assay}

To evaluate whether exogenous KL $\gamma$ increases colony formation, a colony formation assay was performed. Cells were seeded in a 6-well plate at a density of 2,000 cells/well in serum-containing medium and incubated at $37^{\circ} \mathrm{C}$ in an atmosphere of $5 \% \mathrm{CO}_{2}$ with or without $50 \mathrm{ng} / \mathrm{mL} \mathrm{KL} \gamma$. After two weeks, colonies were fixed with methanol and stained with $0.1 \%$ crystal violet (Sigma-Aldrich, St Louis, MO, USA) according to the manufacturer's instructions. The number of visible colonies was measured for each well.

\section{Soft agar colony formation assay}

To examine anchorage-independent growth, a soft agar colony formation assay was performed. A base agar layer was prepared using a 1.2\% agar solution (Difco, Franklin Lakes, NJ, USA) mixed with an equal volume of $2 \times$ Dulbecco's modified Eagle's medium (DMEM; SigmaAldrich) with $20 \%$ FBS in a 24 -well culture plate. Cell suspensions $\left(2.5 \times 10^{4}\right.$ cells $\left./ \mathrm{mL}\right)$ were prepared and mixed with both the $1.2 \%$ agar solution and $2 \times$ DMEM with $20 \%$ FBS in the same manner as described above. Exogenous $\mathrm{KL} \gamma(50 \mathrm{ng} / \mathrm{mL})$ or PBS as a control was added to each well and incubation was carried out at $37^{\circ} \mathrm{C}$ in an atmosphere of $5 \% \mathrm{CO}_{2}$. A week after seeding, the number of growing colonies was counted under a microscope.

\section{Animals}

Animal care was in compliance with the recommendations of The Guide for Care and Use of Laboratory Animals (National Research Council) and this study was approved by the animal facility committee at Nara Medical University (protocol ID: 11896). Female athymic BALB/c nu/nu mice, 6 to 8 weeks old, were purchased from Oriental Bio Service (Kyoto, Japan). All mice were maintained under pathogen-free conditions and provided with sterile food and water.

\section{Transfection of small interfering RNA (siRNA)}

For the in vitro study, UM-UC-3 cells were transfected with synthesized KL $\gamma$ siRNA or negative control siRNA (Invitrogen, Life Technologies) with 50 pmol of siRNA and $5 \mu \mathrm{L}$ of Lipofectamine 2000 (Life Technologies) using 6-well plates according to the manufacturer's instructions. After $48 \mathrm{~h}$ of transfection, RNA was extracted and expression of KL $\gamma$ was measured in each cell line.

\section{Xenograft model and intratumoral treatment}

After allowing mice to acclimate to our facility for one week, bladder cancer cells (UM-UC-3; $5 \times 10^{5} /$ tumor) in $50 \mu \mathrm{L}$ RPMI-1640 medium, together with $50 \mu \mathrm{L}$ of Matrigel (Corning Incorporated), were injected into flank of each mouse. Two weeks after cell inoculation, when the tumors reached $5 \mathrm{~mm}$ in diameter, we randomly divided the mice into three groups $(\mathrm{n}=6$ mice per group): control (no treatment), negative control siRNA (10 $\mu \mathrm{g}$ of nontarget siRNA mixed with $1.2 \mu \mathrm{L}$ of in vivo-jetPEI reagent with an N/P ratio of 6 , according to the manufacturer's protocol), and human KL $\gamma$ siRNA $(10 \mu \mathrm{g}$ of siRNA with 
$1.2 \mu \mathrm{l}$ of in vivo-jetPEI reagent with an N/P ratio of 6 , according to the manufacturer's protocol). Treatment was then initiated. KL $\gamma$ siRNA therapy was administered intratumorally once a week for four weeks. To ensure optimal delivery to xenograft tumors, in vivo-jetPEI reagent (Polyplus-transfection Inc., New York City, NY, USA) was used in conjunction with siRNA [38]. Tumor diameters were measured once a week with electronic calipers and tumor volumes were calculated using the following formula: $\left\{(\text { width })^{2} \times\right.$ length $\} / 2\left(\mathrm{~mm}^{3}\right)$. Three days after the last treatment, all mice were euthanized by exsanguination under anesthesia with isoflurane and tumors were harvested for the following experiments.

\section{Immunohistochemistry (IHC) analysis of xenograft tumors}

Tumors were examined by IHC staining analysis as previously described [20]. Briefly, anti-KL $\gamma$ antibody, antiKi-67 antibody (clone MIB-1, ready to use; Dako, Japan), and anti-E-cadherin antibody (3195; rabbit monoclonal, dilution 1/1000; Cell Signaling Technology, Beverly, MA, USA) were used for IHC analysis. Moreover, to identify apoptotic cells by terminal deoxynucleotidyl transferase-mediated dUTP nick end labeling (TUNEL) assay, apoptotic cells in the xenografts were detected using a TUNEL apoptosis detection kit (R\&D Systems, Minneapolis, MN, USA) according to the manufacturer's instructions.

\section{Western blot analysis of xenograft tumors}

Protein was extracted from resected tumors and western blot analysis was performed as previously described [39]. Briefly, for protein extraction, tumor samples were minced and incubated in lysis buffer (250 $\mathrm{mmol} / \mathrm{L}$ Tris- $\mathrm{HCl}$ (pH 6.8), $2 \%$ SDS, and $10 \%$ glycerol) and protein inhibitor cocktail (Sigma-Aldrich). The membranes were incubated for $1 \mathrm{~h}$ with primary anti-Ecadherin rabbit monoclonal antibody (dilution 1/1000), anti-N-cadherin mouse monoclonal antibody (dilution $1 / 500$ ), anti-vimentin rabbit monoclonal antibody (dilution 1/500), anti-phospho-AKT rabbit monoclonal antibody (dilution 1/1000), anti-phospho-ERK1/2 rabbit monoclonal antibody (dilution 1/1000), or anti-actin mouse monoclonal antibody (dilution 1/10,000) as an internal loading control, followed by $1 \mathrm{~h}$ with horseradish peroxidase-conjugated anti-rabbit $\operatorname{IgG}(1: 5,000)$ or anti-mouse $\operatorname{IgG}$ antibody $(1: 20,000)$ (Santa Cruz Biotechnology).

\section{IHC of human samples}

To investigate the expression levels of KL $\gamma$, IHC was performed as previously described [20]. Paraffin- embedded tissues obtained from all 205 patients at the initial TURBT were used in this study to examine the association between KL $\gamma$ expression level and clinicopathological variables. Briefly, the slides were incubated overnight at $4{ }^{\circ} \mathrm{C}$ with anti-KL $\gamma$ antibody (sc137559; goat polyclonal, dilution 1/500; Santa Cruz Biotechnology, Santa Cruz, CA, USA). The slides were counterstained with hematoxylin, dehydrated, and mounted on a cover slide. We evaluated each slide using IHC scores $(\mathrm{IHC}$ score $=$ intensity score + population score; intensity: none $=0$, low $=1$, intermediate $=2$, and high $=3$; population: none $=0,0-25 \%=1,25-50 \%=$ $2,50-75 \%=3$, and $75-100 \%=4)$. The KL $\gamma$ expression was categorized as low or high according to the IHC score as follows: low $=\mathrm{IHC}$ score $\leq 4$; high $=\mathrm{IHC}$ score 5 or 6 . Then the intravesical recurrence-free survival and progression-free survival in NMIBC patients were evaluated. We defined the intravesical progression as to progress from NMIBC to MIBC. Recurrence-free survival, disease-specific survival, and overall survival in MIBC patients were also evaluated.

\section{Statistical analysis}

Statistical analysis was performed using GraphPad Prism 5.0 (GraphPad Software, Inc., San Diego, CA, USA). The figures were also constructed using GraphPad Prism 5.0. Data are expressed by bar charts or box plots. The Student's t-test or the Mann-Whitney $U$ test was applied for statistical analysis, as appropriate. A survival curve was obtained using the Kaplan-Meier method and compared by the log-rank test for each prognostic variable. A multivariate analysis was performed using the Statistical Package for the Social Sciences, version 19 (SPSS Inc., Chicago, IL, USA). A $P$-value of less than 0.05 was considered to be statistically significant.

\section{Abbreviations}

UCB: urothelial carcinoma of the bladder; NMIBC: non-muscle invasive bladder cancer; MIBC: muscle invasive bladder cancer; TURBT: transurethral resection of bladder tumor; KL $\gamma$ : gamma- Klotho; KLa: alphaKlotho; KLb: beta-Klotho; FGF: fibroblast growth factor; EMT: epithelial-to-mesenchymal transition; ATCC: American Type Culture Collection; FBS: fetal bovine serum; PBS: phosphate-buffered saline; RT-PCR: reverse transcription-polymerase chain reaction; GAPDH: Glyceraldehyde 3-phosphate dehydrogenase; siRNA: small interfering RNA; IHC: immunohistochemistry; TUNEL: terminal deoxynucleotidyl transferase-mediated dUTP nick end labeling; IQR: interquartile range; LVI: lymphovascular invasion; INF: infiltration; HR: hazard ratio; CI: confidence interval; FGFR: fibroblast growth factor receptor; HCC: hepatocellular carcinoma. 


\section{Author contributions}

$\mathrm{SH}, \mathrm{MM}, \mathrm{YN}$, and KF contributed to the design of study and writing the manuscript. SH, MM, YT, YM, $\mathrm{SO}, \mathrm{KO}$, and $\mathrm{KI}$ carried out the animal experiments and molecular biology studies. SH, YM, DG, and NT assisted with the acquisition of patients' data. MM and YN performed the statistical tests. MM and KF helped with writing manuscript. MM and YT reviewed pathologic diagnosis of bladder tissues. All authors read and approved the final manuscript.

\section{ACKNOWLEDGMENTS}

We thank Dr. Michihiro Toritsuka (Department of Psychiatry, Nara Medical University, Nara, Japan) for substantial help with taking microscopic pictures and Aya Asano (Department of Pathology, Nara Medical University, Nara, Japan) for the substantial help with intratumoral treatments.

\section{CONFLICTS OF INTEREST}

The authors declare that they have no competing interests.

\section{FUNDING}

This study was funded by JSPS (KAKENHI Grants No. 16K20159 (M.M.) and No. 26861290 (K.F.)) and by 2015-2016 Nara Medical University Grants-in-Aid for Collaborative Research Projects (K.F. and M.M.).

\section{REFERENCES}

1. Hori M, Matsuda T, Shibata A, Katanoda K, Sobue T, Nishimoto H, and Japan Cancer Surveillance Research Group. Cancer incidence and incidence rates in Japan in 2009: a study of 32 population-based cancer registries for the Monitoring of Cancer Incidence in Japan (MCIJ) project. Jpn J Clin Oncol. 2015; 45:884-91. https://doi. org/10.1093/jjco/hyv088.

2. Miyake M, Fujimoto K, Anai S, Ohnishi S, Nakai Y, Inoue T, Matsumura Y, Tomioka A, Ikeda T, Tanaka N, Hirao Y. Clinical significance of heme oxygenase-1 expression in non-muscle-invasive bladder cancer. Urol Int. 2010; 85:355-63. https://doi.org/10.1159/000317785.

3. Shahin O, Thalmann GN, Rentsch C, Mazzucchelli L, Studer UE. A retrospective analysis of 153 patients treated with or without intravesical bacillus Calmette-Guerin for primary stage T1 grade 3 bladder cancer: recurrence, progression and survival. J Urol. 2003; 169:96-100. https:// doi.org/10.1016/S0022-5347(05)64044-X.
4. Nishiyama H, Habuchi T, Watanabe J, Teramukai S, Tada H, Ono Y, Ohshima S, Fujimoto K, Hirao Y, Fukushima M, Ogawa O. Clinical outcome of a large-scale multiinstitutional retrospective study for locally advanced bladder cancer: a survey including 1131 patients treated during 1990-2000 in Japan. Eur Urol. 2004; 45:176-81. https://doi.org/10.1016/j.eururo.2003.09.011.

5. Grossman HB, Natale RB, Tangen CM, Speights VO, Vogelzang NJ, Trump DL, deVere White RW, Sarosdy MF, Wood DP Jr, Raghavan D, Crawford ED. Neoadjuvant chemotherapy plus cystectomy compared with cystectomy alone for locally advanced bladder cancer. N Engl J Med. 2003; 349:859-66. https://doi.org/10.1056/NEJMoa022148.

6. Gupta S, Gill D, Poole A, Agarwal N. Systemic Immunotherapy for Urothelial Cancer: Current Trends and Future Directions. Cancers (Basel). 2017; 9:E15. https://doi. org/10.3390/cancers9020015.

7. Ito $\mathrm{S}$, Fujimori $\mathrm{T}$, Hayashizaki $\mathrm{Y}$, Nabeshima $\mathrm{Y}$. Identification of a novel mouse membrane-bound family 1 glycosidase-like protein, which carries an atypical active site structure. Biochim Biophys Acta. 2002; 1576:341-45. https://doi.org/10.1016/S0167-4781(02)00281-6.

8. Kuro-o M, Matsumura Y, Aizawa H, Kawaguchi H, Suga T, Utsugi T, Ohyama Y, Kurabayashi M, Kaname T, Kume E, Iwasaki H, Iida A, Shiraki-Iida T, et al. Mutation of the mouse klotho gene leads to a syndrome resembling ageing. Nature. 1997; 390:45-51. https://doi.org/10.1038/36285.

9. Ito S, Kinoshita S, Shiraishi N, Nakagawa S, Sekine S, Fujimori T, Nabeshima YI. Molecular cloning and expression analyses of mouse betaklotho, which encodes a novel Klotho family protein. Mech Dev. 2000; 98:115-19. https://doi.org/10.1016/S0925-4773(00)00439-1.

10. Kurosu H, Kuro-O M. The Klotho gene family as a regulator of endocrine fibroblast growth factors. Mol Cell Endocrinol. 2009; 299:72-78. https://doi.org/10.1016/j. mce.2008.10.052.

11. Zhou X, Wang X. Klotho: a novel biomarker for cancer. J Cancer Res Clin Oncol. 2015; 141:961-69. https://doi. org/10.1007/s00432-014-1788-y.

12. Wolf I, Levanon-Cohen S, Bose S, Ligumsky H, Sredni B, Kanety H, Kuro-o M, Karlan B, Kaufman B, Koeffler HP, Rubinek T. Klotho: a tumor suppressor and a modulator of the IGF-1 and FGF pathways in human breast cancer. Oncogene. 2008; 27:7094-105. https://doi.org/10.1038/ onc.2008.292.

13. Chen B, Wang X, Zhao W, Wu J. Klotho inhibits growth and promotes apoptosis in human lung cancer cell line A549. J Exp Clin Cancer Res. 2010; 29:99. https://doi. org/10.1186/1756-9966-29-99.

14. Doi S, Zou Y, Togao O, Pastor JV, John GB, Wang L, Shiizaki K, Gotschall R, Schiavi S, Yorioka N, Takahashi M, Boothman DA, Kuro-o M. Klotho inhibits transforming growth factor-beta1 (TGF-beta1) signaling and suppresses 
renal fibrosis and cancer metastasis in mice. J Biol Chem. 2011; 286:8655-65. https://doi.org/10.1074/jbc. M110.174037.

15. Zhu Y, Xu L, Zhang J, Xu W, Liu Y, Yin H, Lv T, An H, Liu L, He H, Zhang H, Liu J, Xu J, Lin Z. Klotho suppresses tumor progression via inhibiting PI3K/Akt/GSK3ß/ Snail signaling in renal cell carcinoma. Cancer Sci. 2013; 104:663-71. https://doi.org/10.1111/cas.12134.

16. Xie B, Zhou J, Yuan L, Ren F, Liu DC, Li Q, Shu G. Epigenetic silencing of Klotho expression correlates with poor prognosis of human hepatocellular carcinoma. Hum Pathol. 2013; 44:795-801. https://doi.org/10.1016/j. humpath.2012.07.023.

17. Poh W, Wong W, Ong H, Aung MO, Lim SG, Chua BT, Ho HK. Klotho-beta overexpression as a novel target for suppressing proliferation and fibroblast growth factor receptor-4 signaling in hepatocellular carcinoma. Mol Cancer. 2012; 11:14. https://doi. org/10.1186/1476-4598-11-14.

18. Feng S, Dakhova O, Creighton CJ, Ittmann M. Endocrine fibroblast growth factor FGF19 promotes prostate cancer progression. Cancer Res. 2013; 73:2551-62. https://doi. org/10.1158/0008-5472.CAN-12-4108.

19. Ye X, Guo Y, Zhang Q, Chen W, Hua X, Liu W, Yang Y, Chen G. $\beta$ Klotho suppresses tumor growth in hepatocellular carcinoma by regulating Akt/GSK-3 $\beta /$ cyclin D1 signaling pathway. PLoS One. 2013; 8:e55615. https://doi. org/10.1371/journal.pone.0055615.

20. Hori S, Miyake M, Onishi S, Tatsumi Y, Morizawa Y, Nakai Y, Anai S, Tanaka N, Fujimoto K. Clinical significance of $\alpha$ - and $\beta$-Klotho in urothelial carcinoma of the bladder. Oncol Rep. 2016; 36:2117-25. https://doi.org/10.3892/ or.2016.5053.

21. Kim J, Eskiocak U, Stadler G, Lou Z, Kuro-o M, Shay JW, Wright WE. Short hairpin RNA screen indicates that Klotho beta/FGF19 protein overcomes stasis in human colonic epithelial cells. J Biol Chem. 2011; 286:43294-300. https:// doi.org/10.1074/jbc.M111.267641.

22. Trošt N, Peña-Llopis S, Koirala S, Stojan J, Potts PR, Fon Tacer K, Martinez ED. $\gamma$ Klotho is a novel marker and cell survival factor in a subset of triple negative breast cancers. Oncotarget. 2016; 7:2611-28. https://doi.org/10.18632/ oncotarget.6006.

23. Fon Tacer K, Bookout AL, Ding X, Kurosu H, John GB, Wang L, Goetz R, Mohammadi M, Kuro-o M, Mangelsdorf DJ, Kliewer SA. Research resource: comprehensive expression atlas of the fibroblast growth factor system in adult mouse. Mol Endocrinol. 2010; 24:2050-64. https:// doi.org/10.1210/me.2010-0142.

24. Tiong KH, Mah LY, Leong CO. Functional roles of fibroblast growth factor receptors (FGFRs) signaling in human cancers. Apoptosis. 2013; 18:1447-68. https://doi. org/10.1007/s10495-013-0886-7.
25. Schlessinger J. Common and distinct elements in cellular signaling via EGF and FGF receptors. Science. 2004; 306:1506-07. https://doi.org/10.1126/science.1105396.

26. Miyake M, Ishii M, Koyama N, Kawashima K, Kodama T, Anai S, Fujimoto K, Hirao Y, Sugano K. 1-tert-butyl-3[6-(3,5-dimethoxy-phenyl)-2-(4-diethylamino-butylamino)pyrido[2,3-d]pyrimidin-7-yl]-urea (PD173074), a selective tyrosine kinase inhibitor of fibroblast growth factor receptor-3 (FGFR3), inhibits cell proliferation of bladder cancer carrying the FGFR3 gene mutation along with up-regulation of p27/Kip1 and G1/G0 arrest. J Pharmacol Exp Ther. 2010; 332:795-802. https://doi.org/10.1124/ jpet.109.162768.

27. Miura S, Mitsuhashi N, Shimizu H, Kimura F, Yoshidome H, Otsuka M, Kato A, Shida T, Okamura D, Miyazaki M. Fibroblast growth factor 19 expression correlates with tumor progression and poorer prognosis of hepatocellular carcinoma. BMC Cancer. 2012; 12:56. https://doi. org/10.1186/1471-2407-12-56.

28. Gao L, Wang X, Tang Y, Huang S, Hu CA, Teng Y. FGF19/FGFR4 signaling contributes to the resistance of hepatocellular carcinoma to sorafenib. J Exp Clin Cancer Res. 2017; 36:8. https://doi.org/10.1186/ s13046-016-0478-9.

29. Tiong KH, Tan BS, Choo HL, Chung FF, Hii LW, Tan SH, Khor NT, Wong SF, See SJ, Tan YF, Rosli R, Cheong SK, Leong CO. Fibroblast growth factor receptor 4 (FGFR4) and fibroblast growth factor 19 (FGF19) autocrine enhance breast cancer cells survival. Oncotarget. 2016; 7:57633-50. https://doi.org/10.18632/oncotarget.9328.

30. $\mathrm{Hu} \mathrm{L}$, Cong L. Fibroblast growth factor 19 is correlated with an unfavorable prognosis and promotes progression by activating fibroblast growth factor receptor 4 in advancedstage serous ovarian cancer. Oncol Rep. 2015; 34:2683-91. https://doi.org/10.3892/or.2015.4212.

31. Touat M, Ileana E, Postel-Vinay S, André F, Soria JC. Targeting FGFR Signaling in Cancer. Clin Cancer Res. 2015; 21:2684-94. https://doi.org/10.1158/1078-0432. CCR-14-2329.

32. Chae YK, Ranganath K, Hammerman PS, Vaklavas C, Mohindra N, Kalyan A, Matsangou M, Costa R, Carneiro B, Villaflor VM, Cristofanilli M, Giles FJ. Inhibition of the fibroblast growth factor receptor (FGFR) pathway: the current landscape and barriers to clinical application. Oncotarget. 2017; 8:16052-74. https://doi.org/10.18632/oncotarget.14109.

33. Xu YF, Yang XQ, Lu XF, Guo S, Liu Y, Iqbal M, Ning SL, Yang H, Suo N, Chen YX. Fibroblast growth factor receptor 4 promotes progression and correlates to poor prognosis in cholangiocarcinoma. Biochem Biophys Res Commun. 2014; 446:54-60. https://doi.org/10.1016/j. bbrc.2014.02.050.

34. Zhao H, Lv F, Liang G, Huang X, Wu G, Zhang W, Yu L, Shi L, Teng Y. FGF19 promotes epithelial-mesenchymal 
transition in hepatocellular carcinoma cells by modulating the GSK3 $\beta / \beta$ - catenin signaling cascade via FGFR4 activation. Oncotarget. 2016; 7:13575-13586. https://doi. org/10.18632/oncotarget.6185.

35. McConkey DJ, Choi W, Marquis L, Martin F, Williams MB, Shah J, Svatek R, Das A, Adam L, Kamat A, Siefker-Radtke A, Dinney C. Role of epithelial-to-mesenchymal transition (EMT) in drug sensitivity and metastasis in bladder cancer. Cancer Metastasis Rev. 2009; 28:335-44. https://doi. org/10.1007/s10555-009-9194-7.

36. Baumgart E, Cohen MS, Silva Neto B, Jacobs MA, Wotkowicz C, Rieger-Christ KM, Biolo A, Zeheb R, Loda M, Libertino JA, Summerhayes IC. Identification and prognostic significance of an epithelial-mesenchymal transition expression profile in human bladder tumors. Clin Cancer Res. 2007; 13:1685-94. https://doi. org/10.1158/1078-0432.CCR-06-2330.

37. Cheng T, Roth B, Choi W, Black PC, Dinney C, McConkey DJ. Fibroblast growth factor receptors-1 and -3 play distinct roles in the regulation of bladder cancer growth and metastasis: implications for therapeutic targeting. PLoS One. 2013; 8:e57284. https://doi.org/10.1371/journal. pone. 0057284 .

38. Ito T, Shimada Y, Kan T, David S, Cheng Y, Mori Y, Agarwal R, Paun B, Jin Z, Olaru A, Hamilton JP, Yang $\mathrm{J}$, Abraham JM, et al. Pituitary tumor-transforming 1 increases cell motility and promotes lymph node metastasis in esophageal squamous cell carcinoma. Cancer Res. 2008; 68:3214-24. https://doi.org/10.1158/0008-5472. CAN-07-3043.

39. Anai S, Goodison S, Shiverick K, Hirao Y, Brown $\mathrm{BD}$, Rosser CJ. Knock-down of Bcl-2 by antisense oligodeoxynucleotides induces radiosensitization and inhibition of angiogenesis in human PC-3 prostate tumor xenografts. Mol Cancer Ther. 2007; 6:101-11. https://doi. org/10.1158/1535-7163.MCT-06-0367. 